Bull. Chem. Soc. Ethiop. 2018, 32(3), 421-436.

ISSN 1011-3924

(c) 2018 Chemical Society of Ethiopia and The Authors

Printed in Ethiopia

DOI: https://dx.doi.org/10.4314/bcse.v32i3.2

\title{
SYNTHESIS AND CHARACTERIZATION OF Fe-Al-Mn NANOCOMPOSITE SORBENT FOR PHOSPHATE SORPTION-DESORPTION STUDY
}

\author{
Wakshuma Yadesa ${ }^{1}$, Abi M. Taddesse ${ }^{2 *}$, Kibebew Kibret ${ }^{1}$ and Nigussie Dechassa ${ }^{3}$ \\ ${ }^{1}$ Haramaya University, School of Natural Resource Management and Environmental Sciences, \\ P.O. Box 138, Haramaya, Ethiopia \\ ${ }^{2}$ Haramaya University, Department of Chemistry, P.O. Box 138, Haramaya, Ethiopia \\ ${ }^{3}$ Haramaya University, School of Plant Sciences, P.O. Box 138, Haramaya, Ethiopia
}

(Received April 30, 2018; Revised September 20, 2018; Accepted October 23, 2018)

\begin{abstract}
In this work, we evaluated the potential application of a ternary nanosorbent for predicting phosphate desorption kinetics from soil. Accordingly, ternary mixed oxide nanosorbents with Fe:Al:Mn mole ratios of $3: 3: 1 ; 6: 3: 1$ and $2: 4: 1$ were prepared using simultaneous oxidation and coprecipitation methods. The adsorbents were characterized by X-ray diffraction (XRD), Brunauer-Emmett-Teller (BET) method, scanning electron microscope (SEM) coupled with EDX (energy dispersive X-ray) and Furrier transform infrared spectroscopy (FT-IR). The results indicated that the as-synthesized ternary oxides were either amorphous or crystalline depending on the composition from which the composite was formed, with specific surface area ranging from 41.2 to $243 \mathrm{~m}^{2} \mathrm{~g}^{-1}$. Among the three proportions considered, the one with Fe:Al:Mn in 3:3:1 mole ratio exhibited the highest surface area and was selected for $\mathrm{P}$ sorption-desorption studies. Phosphate removal gradually decreased with the increasing of $\mathrm{pH}$ from 4 to 10.5 . Adsorption isotherms on the adsorbent at $\mathrm{pH} 6.5$ followed the order: Freundlich $>$ Temkin $>$ Dubinin-Radushkevich $>$ Langmuir. At $35{ }^{\circ} \mathrm{C}$, the maximum adsorption capacity for the adsorbent was found to be $49.95 \mathrm{mg} \mathrm{g}^{-1}$. The effect of coexisting anions on phosphate sorption followed the order: $\mathrm{SiO}_{3}{ }^{2-}>\mathrm{CO}_{3}{ }^{2-}>\mathrm{SO}_{4}{ }^{2-}>\mathrm{NO}_{3}{ }^{-}$and this is closely correlated with charge-to-radius ratios of the anions. The kinetic data were described better by the pseudo-second-order adsorption model. The asobtained nanocomposite sorbent with good specific affinity towards phosphate is a promising adsorbent for soil $\mathrm{P}$ desorption studies.
\end{abstract}

KEY WORDS: Nanostructure, Phosphate, Desorption kinetics, Ternary oxide, Adsorption isotherm

\section{INTRODUCTION}

Phosphorus (P) deficiency is a universal constraint to plant growth and often constitute the second most important soil fertility problem in many soils arround the world [1]. On the other hand, soils receiving successive applications of fertilizer $\mathrm{P}$ or manure over a long-term can accumulate large amounts of residual $\mathrm{P}$. This represents not only an uneconomic practice, due to limited phosphate reserves expected to exhaust between 60 to 130 years [2], but also the risk of potential for $\mathrm{P}$ loss to surface waters via overland or subsurface flow and intern accelerate freshwater eutrophication [3].

Numerous approaches have been developed for $\mathrm{P}$ removal each with its own merit and demerit. For example, chemical precipitation and biological removal in general are not able to meet the stringent effluent standards while ion exchange, electrodialysis and reverse osmosis require high investment and operation costs $[4,5]$. Compared with these techniques, adsorption methods proved to be more promising due to their low cost, effective treatment in dilute solutions, and high uptake capacity. Another attractive feature of this technique is that the nutrient-loaded filters can be used in agriculture as phosphate fertilizers [6], promoting judiciuous use of this non-renewable natural resource.

Nanocomposite sorbents are one category of nanomaterials synthesized for applications in sorption processes to extract (remove) ions and various contaminants from environment, water

*Corresponding author. E-mail: abi92003@yahoo.com

This work is licensed under the Creative Commons Attribution 4.0 International License 
and soil. Transition metal oxides are one of the most important compounds for synthesis of nanocomposite sorbents. Iron oxides are one of the most important transition metal oxides used to synthesize nanocomposite sorbent either in pure form or with other transition metal oxides [7]. Although iron oxides alone have several applications, some of their adsorptive properties can be improved when prepared in mixture with other metal oxides such as $\mathrm{Al}(\mathrm{III}), \mathrm{Cr}(\mathrm{III})$, $\mathrm{Cu}(\mathrm{II}), \mathrm{Mn}(\mathrm{IV}), \mathrm{Ti}(\mathrm{IV})$ and $\mathrm{Zr}(\mathrm{IV})$ [4, 8-11].

Considerable number of reports has shown that excellent and efficient phosphorus adsorbents are all characterized by their high iron, alumina, calcium and manganese contents [4, $5,12]$. Thus, substrates with high contents of these materials can be efficient phosphate sinks in immobilizing phosphate from soils and water bodies. The surface property studies of mixed metal oxides are given importance because they mimic the natural systems like soils more closely than their individual component [13]. Since naturally occurring oxides are typically coprecipitated mixtures, it is reasonable to postulate that co-precipitated Al-Fe-Mn hydr(oxides) are likely to play a major role in the geochemical cycling of nutrients and contaminants. Extensive reports have been documented using binary oxide systems where iron oxide is a component, however, there is a paucity of information in the literature regarding ternary oxide sorbents for phosphate sorption [14].

Our research group recently reported nanocrystalline mixed metal oxides $[4,5]$ and confirmed their ability for phosphate sorption application in artificially contaminated aqueous system. However, there is no report so far on P sorption behavior of the as-synthesized Fe-AlMn ternary composite when placed in soil solution, a step that is required to design a novel method for predicting long-term $\mathrm{P}$ desorption kinetics from soil. In addition, the ternary system we synthesized previously had a well crystalline nature but relatively low specific surface area $\left(49.5 \mathrm{~m}^{2} \mathrm{~g}^{-1}\right)$. In the present work, we attempted to prepare a ternary composite with enhanced specific surface area $\left(243 \mathrm{~m}^{2} \mathrm{~g}^{-1}\right)$ and evaluated the sorption-desorption behavior of this ternary nanosorbent in soil solution.

\section{EXPERIMENTAL}

Synthesis of Fe-Al-Mn nanocomposite sorbent

The nanocomposite sorbent of Fe-Al-Mn was synthesized by oxidation and coprecipitation method [12]. The chemicals used in the synthesis were potassium permanganate $\left(\mathrm{KMnO}_{4}\right)$, aluminum chloride $\left(\mathrm{AlCl}_{3}\right)$ and ferrous sulfate heptahydrate $\left(\mathrm{FeSO}_{4} \cdot 7 \mathrm{H}_{2} \mathrm{O}\right)$. In addition, other chemicals were also used such as potassium dihydrogen orthophosphate $\left(\mathrm{KH}_{2} \mathrm{PO}_{4}\right)$, sodium hydroxide $(\mathrm{NaOH})$, sodium chloride $(\mathrm{NaCl})$, sodium sulfate $\left(\mathrm{Na}_{2} \mathrm{SO}_{4}\right)$, sodium bicarbonate $\left(\mathrm{NaHCO}_{3}\right)$ and sodium silicate $\left(\mathrm{Na}_{2} \mathrm{SiO}_{3}\right)$. The above chemicals and reagents were all analytical grade and used with no further purification. All solutions were prepared using deionized water. The nanocomposite sorbents were prepared in three different molar ratios of the metals (Table 1). These were Fe(II) : Al (III) : Mn (VII) molar ratios of 3:3:1, 6:3:1 and 2:4:1.

The main preparation procedures were as follows. For the 3:3:1 molar ratio, $2.37 \mathrm{~g} \mathrm{KMnO}_{4}$ was dissolved in a $200 \mathrm{~mL}$ of deionized water; $6.01 \mathrm{~g} \mathrm{AlCl}_{3}$ and $12.51 \mathrm{~g} \mathrm{FeSO}_{4} \cdot 7 \mathrm{H}_{2} \mathrm{O}$ were dissolved in another $200 \mathrm{~mL}$ of deionized water. For the $6: 3: 1$ molar ratio, $2.37 \mathrm{~g} \mathrm{KMnO}_{4}$ was dissolved in a $200 \mathrm{~mL}$ of deionized water; $6.01 \mathrm{~g} \mathrm{AlCl}_{3}$ and $25.02 \mathrm{~g} \mathrm{FeSO}_{4} \cdot 7 \mathrm{H}_{2} \mathrm{O}$ were dissolved in another $200 \mathrm{~mL}$ of deionized water. For the 2:4:1 molar ratio, $2.37 \mathrm{~g} \mathrm{KMnO}_{4}$ was dissolved in a $200 \mathrm{~mL}$ of deionized water; $8.01 \mathrm{~g} \mathrm{AlCl}_{3}$ and $8.34 \mathrm{~g} \mathrm{FeSO}_{4} \cdot 7 \mathrm{H}_{2} \mathrm{O}$ were dissolved in another $200 \mathrm{~mL}$ of deionized water. Under vigorous magnetic stirring, the mixture solution of $\mathrm{AlCl}_{3}$ and $\mathrm{FeSO}_{4}$ was added into the $\mathrm{KMnO}_{4}$ solution, and simultaneously $5 \mathrm{M} \mathrm{NaOH}$ solution was added drop wisely to keep the solution $\mathrm{pH}$ in the range of 7 - 8. After addition, the formed suspension was continuously stirred for $1 \mathrm{~h}$, aged at room temperature for $12 \mathrm{~h}$, and then washed repeatedly with deionized water. The suspensions were dried at $120{ }^{\circ} \mathrm{C}$ in an oven. The obtained dry materials were stored in a desiccator for further use. 
Table 1. The three different proportions of the metals, Fe, Al and Mn used to synthesize the nanocomposite sorbent.

\begin{tabular}{|l|l|l|}
\hline Molar ratios & Percentages & Mass of precursor salts (g) \\
\hline Fe:Al:Mn: 3:3:1 & Fe:Al:Mn: 43:43:14 & Fe:Al:Mn: 12.51:6.01:2.37 \\
\hline Fe:Al:Mn: 6:3:1 & Fe:Al:Mn: 60:30:10 & Fe:Al:Mn: 25.02:6.01:2.37 \\
\hline Fe:Al:Mn: 2:4:1 & Fe:Al:Mn: 29:57:14 & Fe:Al:Mn: 8.34:8.01:2.37 \\
\hline
\end{tabular}

Characterization of the nanocomposite sorbent

Particle size $\left(\mathrm{D}_{\mathrm{s}}\right)$ of the nanocomposite sorbent of the solid-phase Fe-Al-Mn ternary metal hydr(oxide) was determined by X-ray diffraction (XRD) method. The $\mathrm{D}_{\mathrm{s}}$ was calculated from the XRD diffractograms according to the Dubye Scherrer equation [15].

$$
D_{s}=\frac{0.9 \lambda}{\beta \cos \theta}
$$

where, $D_{s}$ is mean crystallite size $(\mathrm{nm}), \lambda$ wavelength of the incident radiation $(\lambda=0.15405 \mathrm{~nm})$, $\beta$ pure diffraction broadening (radians) and $\theta$ the Bragg angle (degrees, half-scattering angle).

The pure diffraction broadening $(\beta)$ is taken as the full width at half maximum of the major diffraction band (FWHM). The XRD pattern was obtained through a $\mathrm{CuK} \alpha$ target radiation. Nitrogen adsorption/desorption isotherms were measured at $-196{ }^{\circ} \mathrm{C}$ in a micromeritics ASAP 2420 device. Before the registration of the isotherms, samples were degassed at $350{ }^{\circ} \mathrm{C}$ under high vacuum for at least $18 \mathrm{~h}$. Specific surface areas were estimated by the Brunauer, Emmett and Teller (BET) method. Morphology of the solids and particle size distributions were determined by scanning electron microscopy (SEM) with an EDX (energy dispersive analysis of $\mathrm{X}$-ray) detector. Functional groups (surface charges) of nanosorbent were characterized using Fourier transform infrared spectroscopy (FT-IR). The effect of ionic strength on P sorption on the nanosorbent was determined as per [12].

\section{Sorption study}

The three nanocomposite sorbents, $\mathrm{S}_{3: 3: 1}$ (for $\mathrm{Fe}: \mathrm{Al}: \mathrm{Mn}=3: 3: 1$ ), $\mathrm{S}_{6: 3: 1}$ (for $\mathrm{Fe}: \mathrm{Al}: \mathrm{Mn}=6: 3: 1$ ) and $\mathrm{S}_{2: 4: 1}$ (for $\mathrm{Fe}: \mathrm{Al}: \mathrm{Mn}=2: 4: 1$ ) were used to generate three sets of adsorption data. The adsorption data were experimentally obtained by a series of batch tests for adsorption of phosphate in solutions with different initial concentrations $\left(\mathrm{C}_{0}=5.0,10.0,25.0,50.0 \mathrm{mgPL}^{-1}\right)$. For the equilibrium experiments, about $0.15 \mathrm{~g}$ adsorbent powder was added into $100 \mathrm{~mL}$ phosphate solution in a polypropylene bottle with various initial concentrations mentioned here. After being shaken at $25^{\circ} \mathrm{C}$ for $3 \mathrm{~h}$, the solutions were removed by filtering through Whatman 42 filter paper and the equilibrium phosphate concentrations $\left(\mathrm{C}_{\mathrm{e}}, \mathrm{mgPL}^{-1}\right)$ in the filtrates were analyzed by UV spectrometer. The amount of phosphate adsorbed at equilibrium $\left(\mathrm{Q}_{\mathrm{e}}, \mathrm{mg} \mathrm{P} \mathrm{g}^{-1}\right)$ was calculated by equation (2).

$Q_{e}=\frac{\left(C_{0}-C_{e}\right) V}{m}$

where $\mathrm{C}_{\mathrm{o}}$ and $\mathrm{C}_{\mathrm{e}}\left(\mathrm{mgPL}^{-1}\right)$ are the initial and equilibrium phosphate concentrations, respectively, $\mathrm{V}(\mathrm{L})$ is the volume of the solution and $\mathrm{m}(\mathrm{g})$ is the mass of the adsorbent.

\section{Adsorption kinetic studies}

Kinetics of the adsorption process was investigated at $25^{\circ} \mathrm{C}$. A $100 \mathrm{~mL}$ phosphate solutions with initial concentrations of 5.0, 10.0, 25.0 and $50.0 \mathrm{mgL}^{-1}$ were added into polypropylene bottles. The initial $\mathrm{pH}$ values of the solutions were adjusted to 6.5 . Then $0.15 \mathrm{~g}$ of the selected adsorbent $\left(\mathrm{S}_{3: 3: 1}\right)$ was added to the suspension. The solutions with an ionic strength of $0.01 \mathrm{M}$ $\mathrm{NaCl}$ were equilibrated for $42 \mathrm{~h}$ with shaking on mechanical shaker at $120 \mathrm{rpm}$. Approximately 
$10 \mathrm{~mL}$ aliquots were taken from the suspensions at different intervals $(1,3,9,18,36$, and $42 \mathrm{~h})$ for the analysis of adsorbed phosphate concentrations. The kinetic data were fitted using the pseudo-first-order model and pseudo-second-order model. The following kinetic rate equations were used to fit the kinetic data.

Pseudo-first-order model:

$d q_{t} /_{d t}=k_{1}\left(q_{e}-q_{t}\right)$

Pseudo-second-order model:

$d q_{t} / d t=k_{2}\left(q_{e}-q_{t}\right)^{2}$

where $\mathrm{q}_{\mathrm{t}}$ is the adsorbed amount at time $\mathrm{t}\left(\mathrm{mg} \cdot \mathrm{P} \cdot \mathrm{g}^{-1}\right), \mathrm{q}_{\mathrm{e}}$ is the adsorbed amount at equilibrium, $\mathrm{k}_{1}$ $\left(\mathrm{min}^{-1}\right)$ and $\mathrm{k}_{2}\left(\mathrm{~g}(\mathrm{mg} \cdot \mathrm{min})^{-1}\right)$ is the equilibrium rate constants of pseudo-first-order model and pseudo-second-order model, respectively.

After specifying the initial and boundary conditions as $t=0, q_{t}=0 ; t=t, q_{t}=q_{t}$, the kinetic rate equations can be transformed as follows:

Linearized pseudo-first-order model:

$\ln \left(q_{e}-q_{t}\right)=\ln q_{e}-k_{1} t$

Linearized pseudo-second-order model:

$t / q_{t}=1 / k_{2} q_{e}^{2}+t / q_{e}$

Then, equations (5) and (6) were used to plot the adsorption isotherm curves for the pseudo-first order and pseudo-second order kinetics respectively.

\section{Adsorption isotherm}

Adsorption isotherm at varying temperatures $\left(15,25,35^{\circ} \mathrm{C}\right)$ and initial $\mathrm{pH}$ of 6.5 was studied by varying the initial phosphate concentration [4]. In each experiment, $100 \mathrm{~mL}$ solution containing different concentrations of phosphate $\left(\mathrm{C}_{0}=0.5,1.0 \quad 5.0,10.0,25.0,75.0\right.$ and $100.0 \mathrm{mgPL}^{-1}$ were added into the $200 \mathrm{~mL}$ polyethylene bottles and then $0.15 \mathrm{~g}$ of adsorbent was added into the bottles and stoppered. The experiments were carried out at a constant ionic strength $(0.01 \mathrm{M}$ $\mathrm{NaCl}$ solution). The solutions were shaken at $120 \mathrm{rpm}$ on a mechanical shaker at different temperatures for $24 \mathrm{~h}$. The two-parameter adsorption isotherms of Langmuir, Freundlich, Dubinin-Radushkevich and Temkin isotherms were used to fit the experimental data. The nonlinear and linear forms of the four isotherm models are presented in Table 2.

Table 2. Non-linear and linear forms of the isotherm models.

\begin{tabular}{|c|c|c|}
\hline Isotherm model's name & Non-linear forms & Linear forms \\
\hline Langmuir & $Q_{e}=Q_{m} K_{L} \frac{C_{e}}{1+K_{L} C_{e}}$ & $\frac{C_{e}}{Q_{e}}=\frac{1}{Q_{m} K_{L}}+\frac{C_{e}}{Q_{m}}$ \\
\hline Freundlich & $Q_{e}=K_{F} C_{e}^{\frac{1}{n}}$ & $\ln Q_{e}=\ln K_{F}+\frac{1}{n} \ln C_{e}$ \\
\hline Dubinin-Radushkevich & $\begin{array}{c}Q_{e}=Q_{S} \exp \left(-K_{A D} \varepsilon^{2}\right) \\
\left(\varepsilon=\mathrm{R} \ln \left(1+\frac{1}{\mathrm{C}_{e}}\right)\right.\end{array}$ & $\ln Q_{e}=\ln Q_{s}-K_{D} \varepsilon^{2}$ \\
\hline Temkin & $\begin{array}{c}Q_{e}=\frac{R T}{b} \ln A_{T}+\frac{R T}{b} \ln C_{e} \\
\left(B=\frac{R T}{b}\right)\end{array}$ & $Q_{e}=B \ln A_{T}+B \ln C_{e}$ \\
\hline
\end{tabular}

Bull. Chem. Soc. Ethiop. 2018, 32(3) 
By plotting $\mathrm{C}_{\mathrm{e}} / \mathrm{Q}_{\mathrm{e}}$ against $\mathrm{C}_{\mathrm{e}}$, the Langmuir constants $K_{L}$ and $Q_{m}$ were predicted; by plotting $\ln \left(\mathrm{Q}_{\mathrm{e}}\right)$ against $\ln \left(\mathrm{C}_{\mathrm{e}}\right)$, the value of the Freundlich constant $K_{F}$ and $\mathrm{n}$ were determined; by plotting $\ln \left(\mathrm{Q}_{\mathrm{e}}\right)$ against $\varepsilon^{2}$, the values of the Dubinin-Radushkevich constants $K_{D}$ and $Q_{s}$ were estimated; and by plotting $\mathrm{Q}_{\mathrm{e}}$ against $\ln \left(\mathrm{C}_{\mathrm{e}}\right)$, the values of the Temkin constants $\mathrm{A}_{\mathrm{T}}$ and $B$ can be obtained.

\section{Effect of $p H$, ionic strength and coexisting anions}

The effect of ionic strength on the phosphate adsorption was investigated by adding $0.15 \mathrm{~g}$ of the adsorbent sample into a stoppered polyethylene bottles containing $100 \mathrm{~mL}$ of $10 \mathrm{mgL}^{-1}$ phosphate solution. The ionic strength of the solutions varied from 0.001 to $0.1 \mathrm{M}$ by adding $\mathrm{NaCl}$. The pH of the solutions was adjusted to $3.5-10.5$. The solutions were shaken at $120 \mathrm{rpm}$ with a mechanical shaker at $25{ }^{\circ} \mathrm{C}$ for $24 \mathrm{~h}$. Then, the adsorbed phosphate concentration was determined. The effects of different competing anions on phosphate adsorption were studied in batch experiment. Analytical grade salts $\mathrm{Na}_{2} \mathrm{SO}_{4}, \mathrm{Na}_{2} \mathrm{SiO}_{3}, \mathrm{NaNO}_{3}$ and $\mathrm{NaHCO}_{3}$ and deionized water were used to prepare the desired anion concentration ranges of 10 to $20 \mathrm{mg} \mathrm{L}^{-1}$. The effects of coexisting anions: sulfate $\left(\mathrm{SO}_{4}^{2-}\right)$ bicarbonate $\left(\mathrm{HCO}_{3}{ }^{-}\right)$, nitrate $\left(\mathrm{NO}_{3}{ }^{-}\right)$and silicate $\left(\mathrm{SiO}_{3}{ }^{2-}\right)$ on phosphate adsorption were investigated at $25{ }^{\circ} \mathrm{C}$ under a fixed adsorbent dose of $0.15 \mathrm{gL}^{-1}$, phosphate concentration of $10 \mathrm{mgL}^{-1}$, and initial solution $\mathrm{pH}$ of 6.5 . The aliquots were shaken in the presence of phosphate for $24 \mathrm{~h}$ at $120 \mathrm{rpm}$. The phosphate adsorbed was measured spectrophotometrically and adsorption percentage in the presence of other anions was compared with its amount adsorbed in the absence of the mentioned anions $[4,5]$.

\section{Phosphate sorption-desorption study from soil solution}

Sorption-desorption of $\mathrm{P}$ in soil was studied by applying analytical grade $\mathrm{KH}_{2} \mathrm{PO}_{4}$ to the soil as follows. Four $1 \mathrm{~kg}$ soil were taken and $0,50,100$ and $150 \mathrm{mg} \mathrm{kg}^{-1} \mathrm{P}$ was added in the form of $\mathrm{KH}_{2} \mathrm{PO}_{4}$ into each of the soils and mixed thoroughly. Three replicate $1 \mathrm{~g}$ soil samples were taken from the $\mathrm{P}$ applied soil samples into $200 \mathrm{~mL}$ polyethylene tubes, and then $80 \mathrm{~mL} 2 \mathrm{mM}$ $\mathrm{CaCl}_{2}$ and $0.3 \mathrm{mM} \mathrm{KCl}$ were added to each tube to keep ionic strength constant. For each of the four treatment triplicate of seven bottles were arranged. Then a total of 84 bottles $(3 \times 7 \times 4)$ were shaken horizontally on an end-over-end shaker at a speed of 120 oscillations per minute (opm). For each treatment the supernatant was taken at $6,12,18,24,30,36$ and $42 \mathrm{~h}$ from one of the bottles. The supernatant was filtered through Whatman No. 42 filter paper. Then the suspension was dissolved by adding $1 \mathrm{~mL}$ concentrated (98\%) sulfuric acid. Phosphorus in solution was colorimetrically determined with the molybdophosphoric blue [16] method using ascorbic acid as a reductant. A standard series and triplicate of blanks of $20 \mathrm{~mL}$ of $50 \mathrm{mM} \mathrm{KCl}$ without soil and without $\mathrm{P}$ and with the same background $\mathrm{Fe}, \mathrm{Al}, \mathrm{Mn}$ and sulfuric acid were included.

Data analysis

The data obtained were statistically analyzed using statistical analysis system (SAS Institute, 2004). Analysis of variance was done using the general linear model (GLM) procedure. The Fisher test was used to determine significant differences at $P \leq 0.001$.

\section{RESULTS AND DISCUSSION}

\section{Structural and textural characterization}

The XRD patterns of the three sorbents are shown in Figure 1. Among the three different proportions, only the composite with $\mathrm{Fe}: \mathrm{Al}: \mathrm{Mn}$ ratio 2:4:1 resulted crystalline state. The remaining combinations provided amorphous phase accompanied by weak intensity peaks evidencing the presence of crystalline domains upon composite formation. For the crystalline 
state $\left(\mathrm{S}_{2: 4: 1}\right)$, the peak at $2 \theta$ value of 27.4 can be accounted for $\beta-\mathrm{MnO}_{2}$; the peaks at $2 \theta$ values of 53.9, 75.3 and 80.5 represent hematite phase of iron oxide $\left(\alpha-\mathrm{Fe}_{2} \mathrm{O}_{3}\right)$ [JCPDS 87-1166/ 96-9000140] whereas peaks at $2 \theta$ values of 31.7 and 56.5 represent maghemite phase $\left(\gamma-\mathrm{Fe}_{2} \mathrm{O}_{3}\right)$ [JCPDS 25-1402/06-9006317] [4, 5, 17, 18]. The alumina $\left(\mathrm{Al}_{2} \mathrm{O}_{3}\right)$ component of the nanocomposite is observed at diffraction peaks of 45.6 and 66.3 [JCPDS 10-0425] [9, 19]. The average crystallite size was estimated for the crystalline phase using Scherer equation the size of which is found to be $77.5 \mathrm{~nm}$. The nanocomposite with 6:3:1 Fe:Al:Mn ratio showed weak peaks at $2 \theta$ values of 27.4 and $63.5\left(\beta-\mathrm{MnO}_{2}\right), 36.4\left(\gamma-\mathrm{Fe}_{2} \mathrm{O}_{3}\right), 45\left(\mathrm{Al}_{2} \mathrm{O}_{3}\right)$ and $53.6\left(\alpha-\mathrm{Fe}_{2} \mathrm{O}_{3}\right)$. In the case of composite comprising $\mathrm{Fe}: \mathrm{Al}: \mathrm{Mn}$ in a ratio $3: 3: 1$, the phase is amorphous. The specific surface area of the as-synthesized composites was determined by using the BET method (Table 3). The most amorphous sample gave the highest surface area probably due to a smaller particle size or a more efficient mixture of the oxides. Surface area is related to particle size, particle morphology, surface texturing and porosity [20]. As shown in Table 4, $\mathrm{S}_{3: 3: 1}$ sorbent with percent composition of $\mathrm{Fe}: \mathrm{Al}: \mathrm{Mn}(43: 43: 14)$ showed the highest specific surface area $\left(243.22 \pm 1.52 \mathrm{~m}^{2} \mathrm{~g}^{-1}\right)$ and this sample was selected for further characterization and sorption studies.

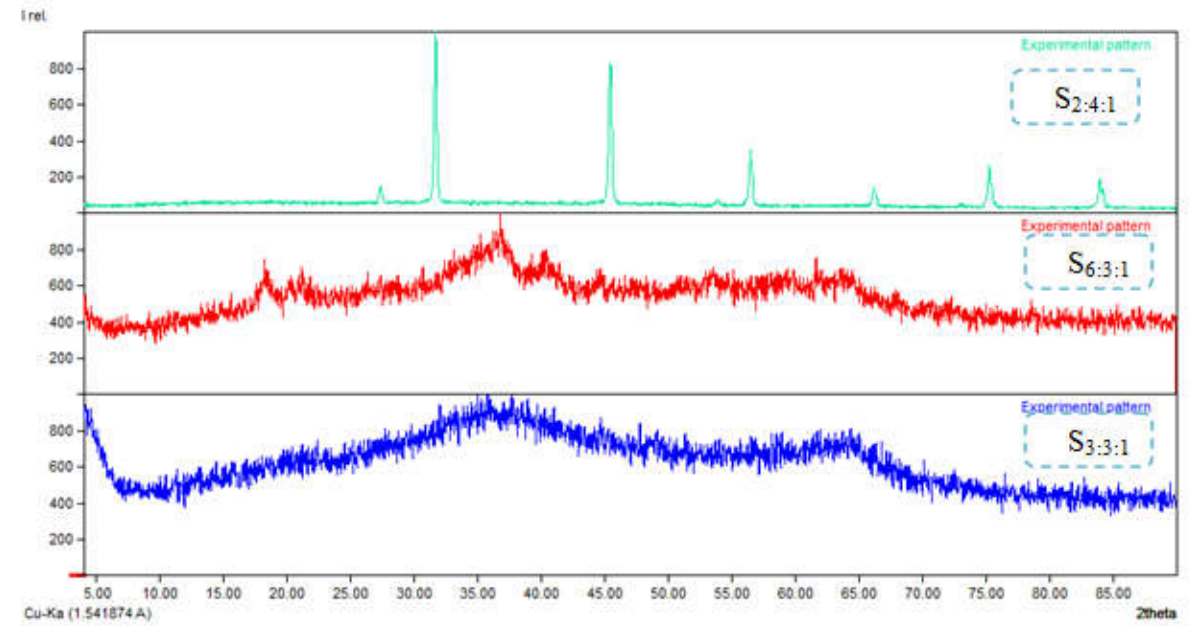

Figure 1. XRD patterns of the nanocomposite sorbent synthesized from different percentages of $\mathrm{Fe}$, Al and Mn. (Weight percent ratios of Fe:Al:Mn - $\mathrm{S}_{2: 4: 1}=29: 57: 14 ; \mathrm{S}_{6: 3: 1}$, = 60:30:10 and $\left.S_{3: 3: 1}=43: 43: 14\right)$.

Table 3. Specific surface area $\left(\mathrm{m}^{2} \mathrm{~g}^{-1}\right)$ of Fe-Al-Mn hydr(oxide) composite sorbent.

\begin{tabular}{|c|c|c|}
\hline \% Composition of Fe:Al:Mn & Sorbent code & Surface area $\left(\mathrm{m}^{2} \mathrm{~g}^{-1}\right)$ \\
\hline $43: 43: 14$ & $\mathrm{~S}_{3: 3: 1}$ & $243.22 \pm 1.52$ \\
\hline $60: 30: 10$ & $\mathrm{~S}_{6: 3: 1}$ & $166.86 \pm 0.74$ \\
\hline $29: 57: 14$ & $\mathrm{~S}_{2: 4: 1}$ & $41.17 \pm 0.33$ \\
\hline
\end{tabular}

Morphology and elemental composition

The morphology and surface element distribution of the adsorbents were characterized by SEMEDX with results shown in Figure 2. All the three composite samples showed no distinct shape. The composites with Fe:Al:Mn ratio of 3:3:1 and 6:3:1 showed similar morphology with textural porosity (a pseudo porosity or void space created between two or more particles of the 
system) whereas the nanocomposite with 2:4:1 ratio exhibited a chunk of aggregated particles of various size.

Energy dispersive X-ray (EDX) analysis was performed to characterize surface elemental compositions. The sample with 3:3:1 ratio showed $\mathrm{Fe}, \mathrm{Al}$ and $\mathrm{Mn}$ in the range 55.7-71.0, 10.423.0 and 15.1-20.1, the average weight percentage being $64.1,18.1$ and 17.1 ; for the sample with 6:3:1 ratio the $\mathrm{Fe}, \mathrm{Al}$ and $\mathrm{Mn}$ ranged from 66.4-75.6, 13.2-18.8, and 6.2-10.2, the average weight percentage being 70.6, 16.7, and 8.0; for the sample with 2:4:1 ratio the $\mathrm{Fe}, \mathrm{Al}$ and $\mathrm{Mn}$ ranged from 28.7-43.7, 8.3-10.8 and 6.24-9.0, the average weight percentage being 36.9, 9.2 and 8.0. The elemental composition of the last sample showed considerable number of impurities that might come from the precursors in particular $\mathrm{AlCl}_{3}$ perhaps due to inefficient washing of the as-obtained sample. The largest fraction in all cases $(\mathrm{Fe})$, however, showed wide range of variation compared to the $\mathrm{Al}$ and $\mathrm{Mn}$ making the nanocomposites heterogeneous.
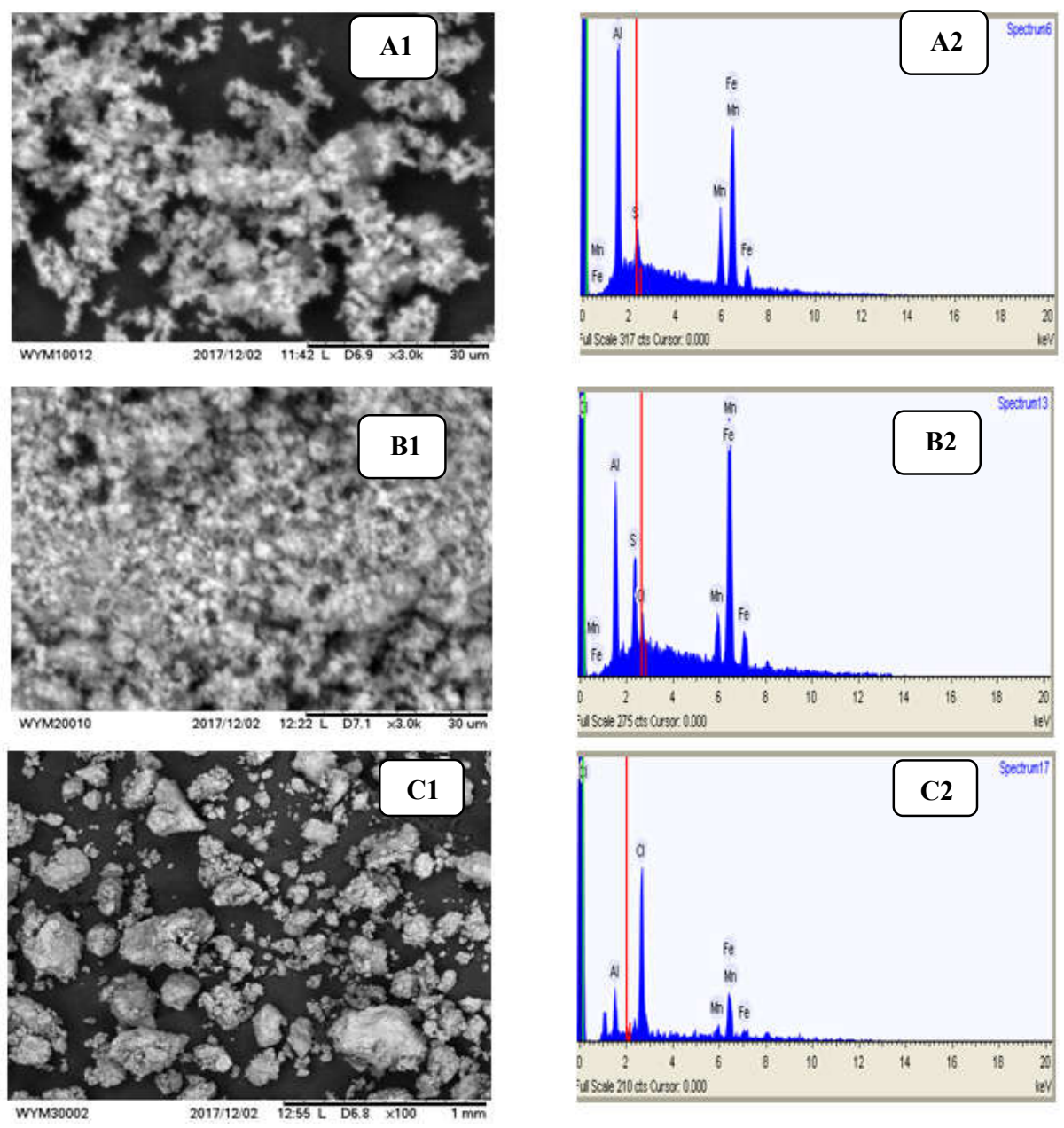

Figure 2. SEM micrograph and EDX spectra of Fe-Al-Mn adsorbents ( $\mathrm{pH}=6.8,40 \mathrm{mg} \mathrm{P} / \mathrm{L})$. A1, $\mathrm{B} 1$ and $\mathrm{C} 1$ are SEM photograph of Fe:Al:Mn in ratios of 3:3:1, 6:3:1 and 4:2:1 and $\mathrm{A} 2, \mathrm{~B} 2$ and $\mathrm{C} 2$ are their corresponding EDX spectra

Bull. Chem. Soc. Ethiop. 2018, 32(3) 


\section{FTIR analysis}

An FTIR spectrum of the selected Fe-Al-Mn nanocomposite is shown in Figure 3. The main absorption peaks were formed at 3411,1628, 1126 and $605 \mathrm{~cm}^{-1}$. Absorption peak at 3411 is due to symmetrical stretching of the $\mathrm{O}-\mathrm{H}$ group while peaks at 1628 and $1126 \mathrm{~cm}^{-1}$ are assigned to bending vibrations of the $\mathrm{O}-\mathrm{H}$ group [13]. The bending vibrations of the $\mathrm{O}-\mathrm{H}$ group may be attributed to the presence of physisorbed water molecules on the surface of the nanocomposite sorbent. Adsorption band centered at $1628 \mathrm{~cm}^{-1}$ is primarily attributed to the bending vibration of hydroxyl groups of iron hydroxides $(\mathrm{Fe}-\mathrm{OH})$ [21]. The band at $605 \mathrm{~cm}^{-1}$ region is assigned to the symmetrical stretching vibration of the mixed metal oxides $\mathrm{M}-\mathrm{O}$ [8].

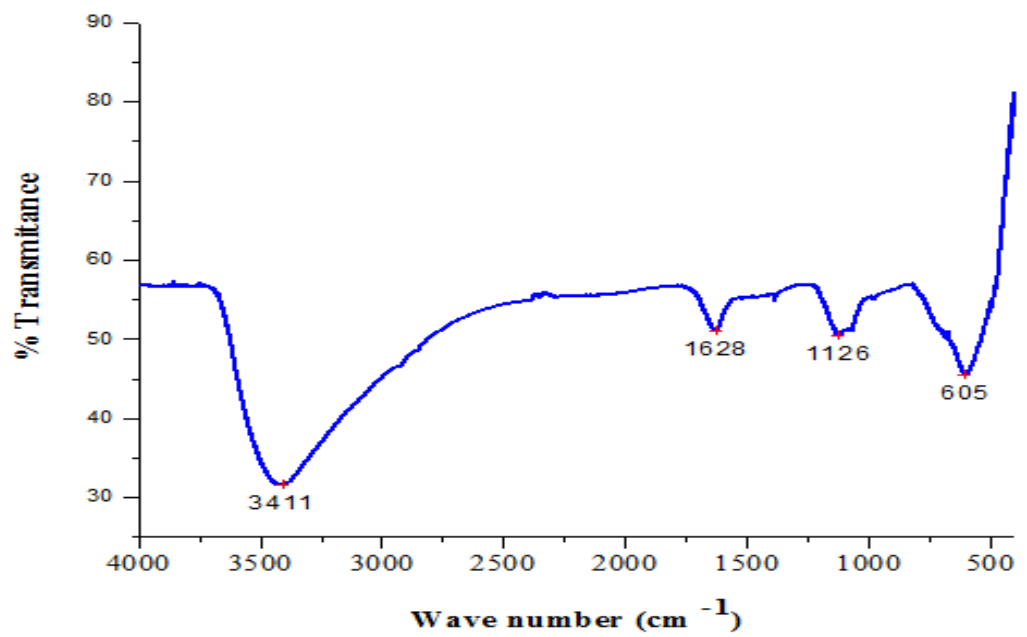

Figure 3. FT-IR spectra of Fe-Al-Mn hydr(oxide) nanocomposite sorbent.

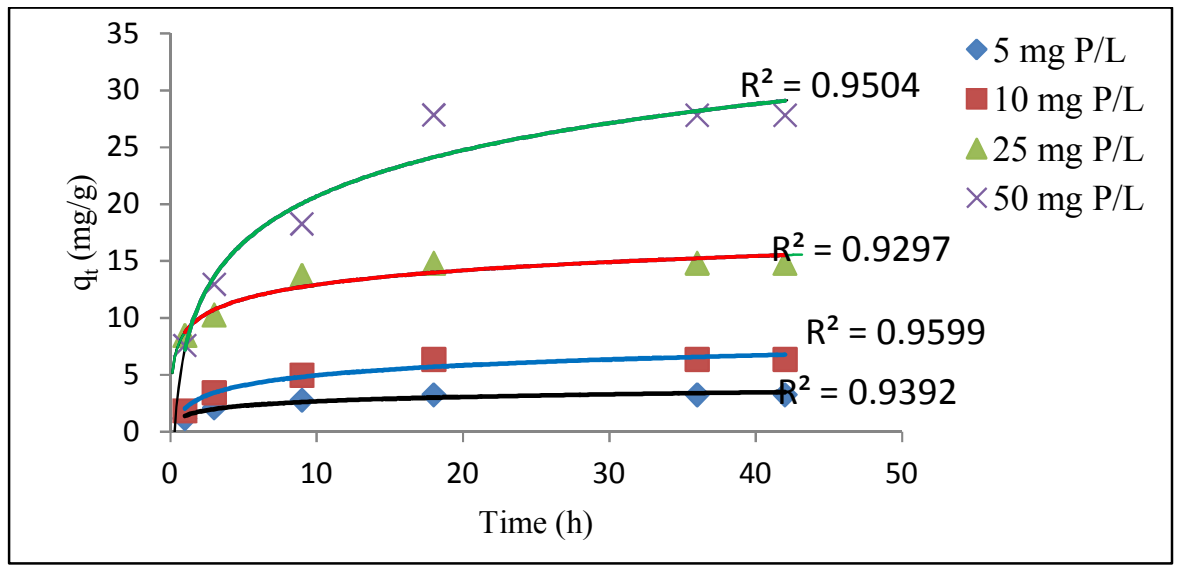

Figure 4. Rates of adsorptions for varying initial concentrations of $\mathrm{PO}_{4}^{-3}$ on Fe-Al-Mn ternary metal hydr(oxide) nanocomposite sorbent. 


\section{Adsorption kinetics}

Adsorption kinetics gives very useful information such as rate, capacity and rate constants in the study of adsorption processes. The phosphate adsorption capacity of the composite sorbents as a function of contact time at different initial phosphate concentrations is shown in Figure 4. As can be seen from the figure, for all of the four initial phosphate concentrations $(5.0,10.0,25.0$ and $50.0 \mathrm{mg} \mathrm{P} \mathrm{L}^{-1}$ ), the phosphate adsorption rates were initially fast and gradually became slower. This observation is consistent with the results of other studies [12, 22, 23]. The amount of adsorbed phosphate increased rapidly with an increase of contact time, and equilibrium was achieved within about $18 \mathrm{~h}$.

Phosphate removal reached above $95 \%$ at equilibrium. After equilibrium, there is only slow increment of phosphate adsorption and the amount of phosphate adsorbed remained almost steady until the end of the experiment $(42 \mathrm{~h})$. Adsorption system is governed by different chemical and physical processes. In the present case, the initial rapid adsorption might be attributed to electrostatic attraction between surface positive charges of the sorbent and negative charges on phosphate ions. This attraction caused the initial transportation of phosphate from solutions onto the surface of adsorbent very fast. After a while, the surface positive charges of the sorbent became saturated with phosphate ions and the next deriving force of the adsorption process became intraparticle diffusion. It is clear that intraparticle diffusion is slower than electrostatic attraction on the surface. This is the likely reason why the adsorption process became slower after equilibrium as reported by [12].

Linear regressions were used to determine the kinetic model parameters (Table 4). The obtained kinetic data were fitted with pseudo-first-order and pseudo-second-order models. For all the four initial phosphate concentrations, the kinetic data were fitted better by the pseudosecond-order adsorption model. This indicates that the dominant deriving force of the adsorption process is chemisorption or chemical bonding between adsorbent positive sites and phosphate ions.

Table 4. The kinetic model parameters for phosphate adsorption on Fe-Al-Mn trimetal hyd(oxide) nanocomposite sorbent.

\begin{tabular}{|c|c|c|c|c|c|c|}
\hline \multirow[t]{2}{*}{$\begin{array}{c}\text { Initial } \mathrm{PO}_{4}^{-3} \\
\text { concentrations, } \\
\mathrm{C}_{0}\left(\mathrm{mgL}^{-1}\right)\end{array}$} & \multicolumn{3}{|c|}{$\begin{array}{l}\text { Pseudo-first order model } \\
\ln \left(\boldsymbol{q}_{e}-\boldsymbol{q}_{t}\right)=\boldsymbol{\operatorname { l n }} \boldsymbol{q}_{e}-\boldsymbol{k}_{1} \boldsymbol{t}\end{array}$} & \multicolumn{3}{|c|}{$\begin{array}{l}\text { Pseudo-second order model } \\
\qquad \frac{\boldsymbol{t}}{\boldsymbol{q}_{t}}=\frac{\mathbf{1}}{\boldsymbol{k}_{2} \boldsymbol{q}_{e}^{2}}+\frac{\mathbf{1}}{\boldsymbol{q}_{e}} \boldsymbol{t}\end{array}$} \\
\hline & $\mathrm{q}_{\mathrm{e}}\left(\mathrm{mgg}^{-1}\right)$ & $\mathrm{k}_{1}\left(\min ^{-1}\right)$ & $\mathrm{R}^{2}$ & $\mathrm{q}_{\mathrm{e}} \quad\left(\mathrm{mgg}^{-1}\right)$ & $\left.\mathrm{k}_{2}(\text { g(mg.min. })^{-1}\right)$ & $\mathrm{R}^{2}$ \\
\hline 5.00 & 30.539 & 0.193 & 0.916 & 3.425 & $1.68 \times 10^{-2}$ & 0.999 \\
\hline 10.00 & 6.814 & 0.184 & 0.926 & 6.849 & $5.40 \times 10^{-2}$ & 0.998 \\
\hline 25.00 & 5.573 & 0.188 & 0.959 & 15.385 & $6.70 \times 10^{-2}$ & 0.999 \\
\hline 50.00 & 2.109 & 0.171 & 0.926 & 31.250 & $8.12 \times 10^{-3}$ & 0.995 \\
\hline
\end{tabular}

A plot of the linearized form of the pseudo-first order model in equation (5) for the sorption of phosphate onto the nanocomposite sorbent at various initial phosphate concentrations for 42 hours is shown in Figure 5. However, the experimental data deviated considerably from the theoretical data as the adsorption time increases. The rate of sorption was assumed to be proportional to the difference between the maximum capacity, $q_{\mathrm{e}}$, at equilibrium and the capacity, $\mathrm{q}_{\mathrm{t}}$, at any time, $t$, of the sorbed phosphate in the pseudo-first order model at the initial reaction stage. Figure 6 shows a plot of the linearized form of the pseudo-second order model in equation (6) for the sorption of phosphate onto the nanocomposite sorbent at various initial phosphate concentrations.

In the pseudo-second order rate law, the correlation coefficients $\left(\mathrm{R}^{2}\right)$ for the linear plots of $t / q_{t}$ against time are greater than 0.995 for all the initial phosphate concentrations throughout the entire contact time of $42 \mathrm{~h}$. This implies that the sorption process under study is not a first order 
reaction, rather, the dominant determining process is chemisorption which involves electrostatic attractions and valence forces through sharing or exchange of electrons between sorbent and sorbate active sites. Therefore, the pseudo-second order model provides the best correlation of the data.

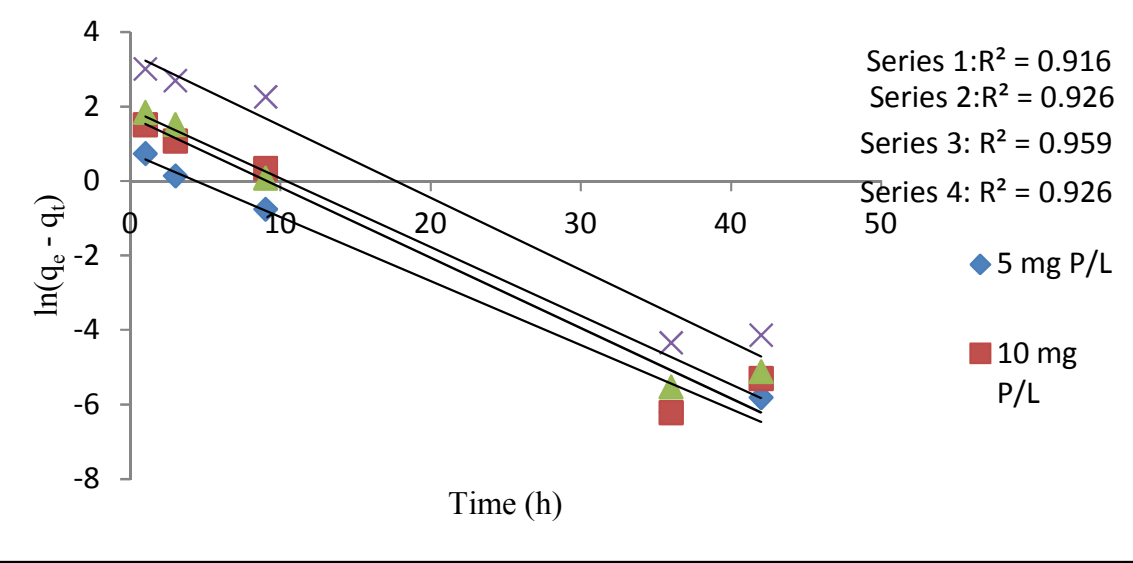

Figure 5. Pseudo-first-order kinetics for varying initial concentrations of $\mathrm{PO}_{4}^{-3}$ adsorption onto Fe-Al-Mn trimetal hydr(oxide) nanocomposite sorbent.

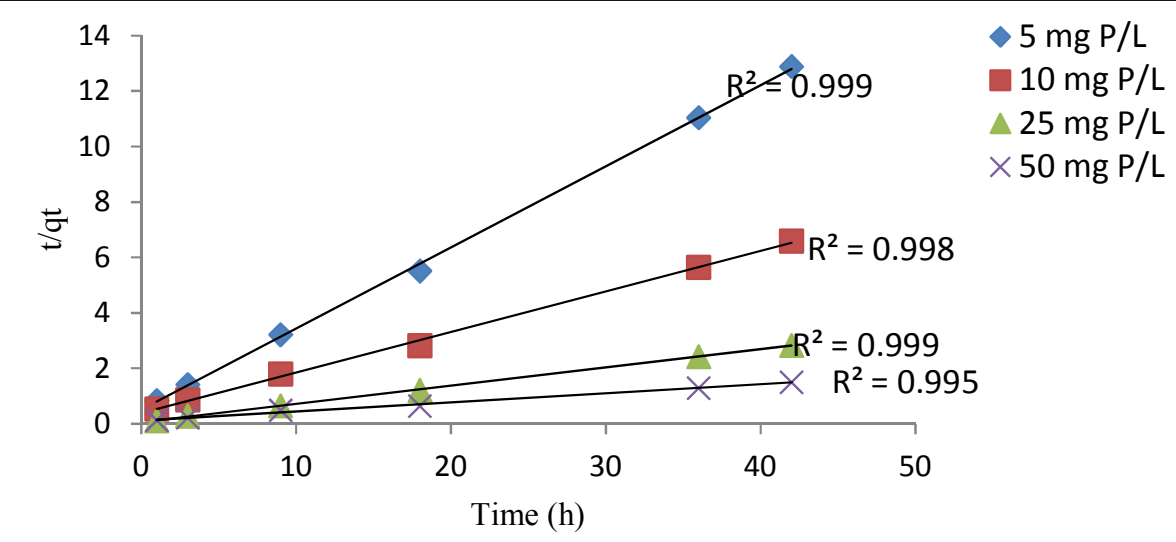

Figure 6. Pseudo-second-order kinetics for varying initial concentrations of $\mathrm{PO}_{4}^{-3}$ adsorption on Fe-Al-Mn trimetal hydr(oxide) nanocomposite sorbent.

\section{Isotherm modeling}

Adsorption isotherm parameters of Langmuir, Freundlich, Dubinin-Radushkevich and Temkin, and their correlation coefficients $\left(\mathrm{R}^{2}\right)$ are indicated in Table 5. For each parameter in the table, the highest $\mathrm{R}^{2}$ values were derived by fitting experimental data into the Freudlich isotherm model $\left(R^{2} \geq 0.984\right)$. The $R^{2}$ values of Temkin isotherm model $\left(R^{2}>0.936\right)$, was higher 
compared to that of Dubinin-Radushkevich and Langmuir isotherm models $\left(R^{2} \leq 0.850\right.$ and $R^{2} \leq$ 0.876 respectively).

Table 5. Langmuir, Freundlich, Dubinin-Radushkevich and Temkin isotherm constants for $\mathrm{PO}_{4}{ }^{3-}$ adsorption on the nanocomposite sorbent of Fe-Al-Mn trimetal hydr(oxide).

\begin{tabular}{|c|c|c|c|c|}
\hline \multirow{2}{*}{\multicolumn{2}{|c|}{ Adsorption isotherm models and Parameters }} & \multicolumn{3}{|c|}{ Adsorptions at three temperatures } \\
\hline & & $15^{\circ} \mathrm{C}$ & $25^{\circ} \mathrm{C}$ & $35^{\circ} \mathrm{C}$ \\
\hline \multirow[t]{3}{*}{ Langmuir } & $\mathrm{q}_{\mathrm{m}}\left(\mathrm{mgg}^{-1}\right)$ & 51.82 & 58.24 & 62.50 \\
\hline & $\mathrm{K}_{\mathrm{L}}\left(\mathrm{Lmg}^{-1}\right)$ & 1.44 & 1.87 & 2.65 \\
\hline & $\mathrm{R}^{2}$ & 0.797 & 0.695 & 0.876 \\
\hline \multirow[t]{4}{*}{ Freundlich } & $\mathrm{K}_{\mathrm{F}}\left(\mathrm{mgg}^{-1}\right)$ & 10.28 & 14.03 & 18.32 \\
\hline & $\mathrm{n}$ & 6.54 & 5.78 & 4.66 \\
\hline & $1 / \mathrm{n}$ & 0.152 & 0.173 & 0.214 \\
\hline & $\mathrm{R}^{2}$ & 0.988 & 0.984 & 0.995 \\
\hline \multirow[t]{3}{*}{ Dubinin-Radushkevich } & $\mathrm{q}_{\mathrm{s}}\left(\mathrm{mgg}^{-1}\right)$ & 4.65 & 12.87 & 16.33 \\
\hline & $\mathrm{K}_{\mathrm{D}}\left(\mathrm{mol}^{2} / \mathrm{KJ}^{2}\right)$ & 0.43 & 0.068 & 0.046 \\
\hline & $\mathrm{R}^{2}$ & 0.716 & 0.617 & 0.850 \\
\hline \multirow[t]{3}{*}{ Temkin } & $\mathrm{A}\left(\mathrm{Lmg}^{-1}\right)$ & 16.56 & 20.42 & 18.44 \\
\hline & $\mathrm{B}$ & 4.82 & 6.79 & 7.60 \\
\hline & $\mathrm{R}^{2}$ & 0.936 & 0.975 & 0.945 \\
\hline
\end{tabular}

The adsorption maxima determined using Freundlich model at the three adsorption temperatures $\left(15,25,35^{\circ} \mathrm{C}\right)$ were $10.28,14.03$ and $18.32 \mathrm{mgPg}^{-1}$, respectively. These values are near the experimental values. This indicates that the modeling of Freundlich for the adsorption system is acceptable. In addition, the adsorption feature of the experimental system indicates that the adsorbing surface of the adsorbent is heterogeneous. As shown in Table 5, the values of $1 / \mathrm{n}$ for the three adsorption temperatures are less than one, implying heterogeneity of the adsorbent surface. In addition, the values of $\mathrm{n}$ lies between one and ten indicating that the sorption process onto the trimetal hydr(oxide) was more favorable than intramolecular diffusion [24].

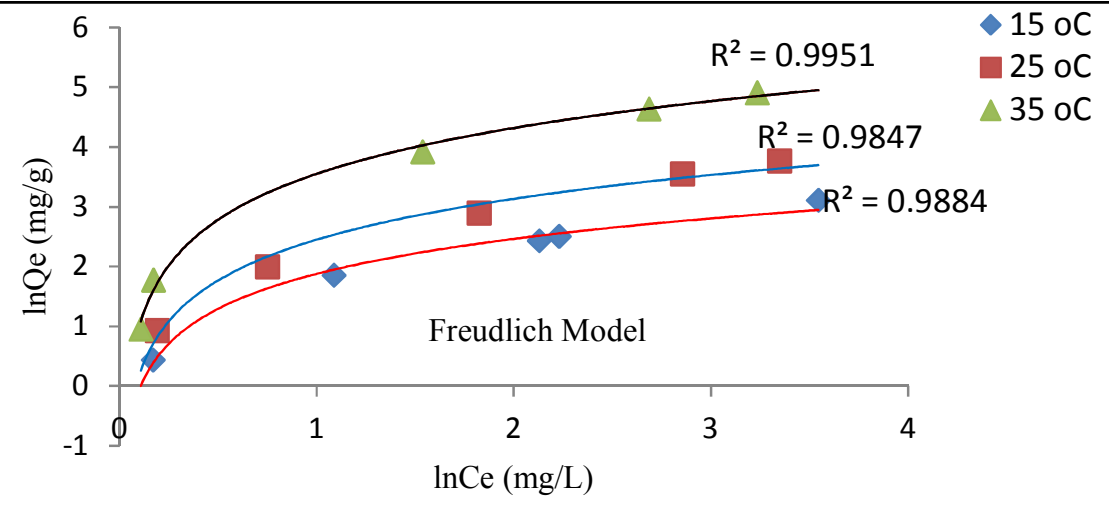

Figure 7. Adsorption isotherm of phosphate on nanocomposite adsorbent of $\mathrm{Fe}-\mathrm{Al}-\mathrm{Mn}$ trimetal hydr(oxide) (adsorbent dose $=0.15 \mathrm{~g} \mathrm{~L}^{-1} ; \mathrm{pH}=6.5,[\mathrm{NaCl}]=0.01 \mathrm{M}$, contact time $=$ $24 \mathrm{~h})$.

The values of the correlation coefficients and theoretical monolayer saturation capacity in the Dubinin-Radushkevich and Langmuir isotherm models are all lower than the experimental 
amounts corresponding to the adsorption isotherm maxima. This indicates the modeling of Dubinin-Radushkevich and Langmuir for the adsorption system is unacceptable. The Langmuir isotherm model which applies better to homogeneous adsorbent surface was not suffice to be applied to the Fe-Al-Mn adsorbent with heterogonous surface. This is why the Freundlich model fitted best as it is commonly used to describe the adsorption characteristics for the heterogeneous surface [25]. In summary, for this work, the order of the isotherm fitting for the three sets of experimental data is Freundlich $>$ Temkin $>$ Langmuir $>$ Dubinin-Radushkevich. The experimental data of phosphate adsorption on the Fe-Al-Mn trimetal hydr(oxide) adsorbent with highest correlation is shown in Figure 7 . At $35^{\circ} \mathrm{C}$, the maximum adsorbed phosphate was $49.95 \mathrm{mgg}^{-1}$ and it is higher than the amount adsorbed by several other adsorbents containing metal oxides for phosphate removal [8, 26-29]. Therefore, the Fe-Al-Mn ternary nanocomposite sorbent could be considered as a potential adsorbent for phosphate adsorption studies as well as phosphate removal in remedying aquatic pollutions.

\section{Effect of $\mathrm{pH}$ and ionic strength}

Generally, phosphate adsorption tended to decrease with increase of $\mathrm{pH}$ from 4 to 10.5 . (Figure 8). Studies made on phosphate removal from water solution gave similar result for phosphate adsorption on other metal oxides $[8,30]$. One of the reasons for this trend was the acid-base properties of the adsorbent surface and the phosphate species in solution at different $\mathrm{pH}$ values. In the $\mathrm{pH}$ ranges 3.5 to $10.5, \mathrm{H}_{2} \mathrm{PO}_{4}{ }^{-}$and $\mathrm{HPO}_{4}{ }^{2-}$ ions were the dominant species (Figure 8). As can be seen from the figure, $\mathrm{H}_{2} \mathrm{PO}_{4}^{-}$was more easily adsorbed on metal oxide surfaces than $\mathrm{HPO}_{4}{ }^{2-}$ since adsorption free energy of the former is lower than the later [31,32]. The effect of ionic strength on phosphate sorption was also assessed. The result obtained showed no noticeable effect on phosphate adsorption with increase of ionic strength from $0.001 \mathrm{M}$ to 0.1 $\mathrm{M}$. This indicates that, adsorption of phosphate onto the surface of the nanocomosite was not dependent on ionic strength of the solution. It is known that out-sphere complex would be formed if the adsorption of anions by metal oxides is strongly dependent on ionic strength [33]. Based on this finding, inner-sphere complexation is presumed to be the possible mechanism of phosphate sorption validating the chemisorptions process predicted in the kinetic studies.

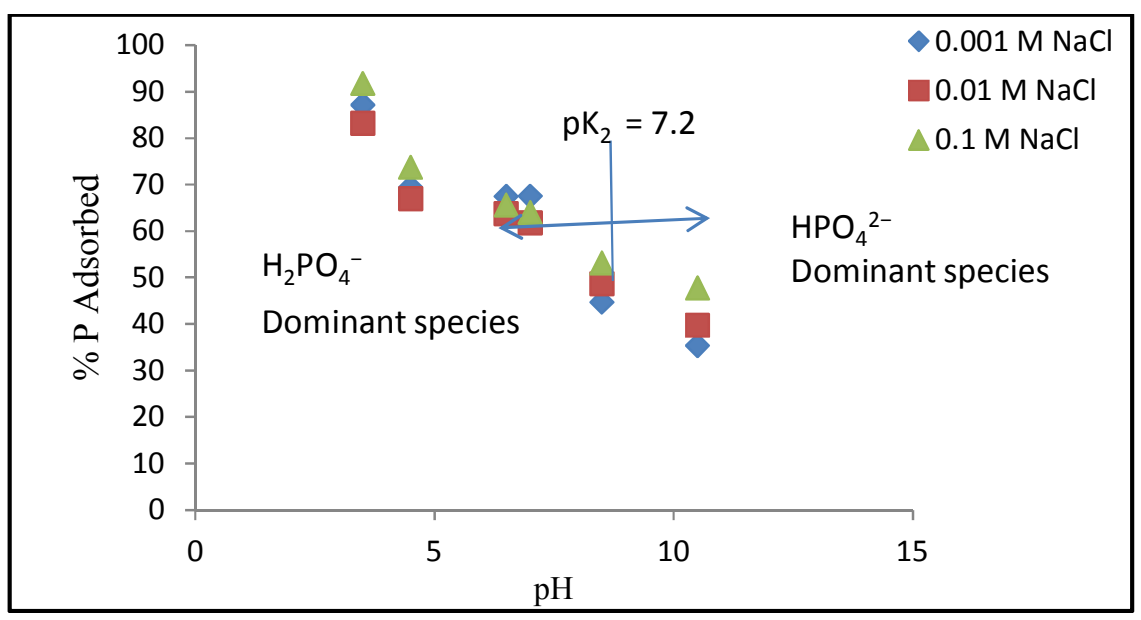

Figure 8. Effect of $\mathrm{pH}$ and ionic strength on phosphate adsorption at $25{ }^{\circ} \mathrm{C}$ (with $10 \mathrm{mg} \mathrm{P} \mathrm{L}^{-1}$, adsorbent dose $=0.15 \mathrm{~g} \mathrm{~L}^{-1}$, contact time $=24 \mathrm{~h}$ ). 


\section{Effect of competing anions}

Effect of interfering ions on phosphate adsorption was assessed by adding a mixture of commonly occurring anions in deionized water such as $\mathrm{SO}_{4}{ }^{2-}, \mathrm{SiO}_{3}{ }^{2-}, \mathrm{NO}_{3}{ }^{-}$and $\mathrm{CO}_{3}{ }^{2-}$ to the phosphate solutions at $\mathrm{pH}$ 6.5. The initial phosphate concentration was $25 \mathrm{mg} \mathrm{L}^{-1}$, while the initial concentrations of other anions varied from $10 \mathrm{mg} \mathrm{L}^{-1}$ to $20 \mathrm{mg} \mathrm{L}^{-1}$. At $25 \mathrm{mg} \mathrm{P} \mathrm{L}^{-1}$ initial phosphate concentration and absence of other competing anions, the adsorption capacity of phosphate onto the nanocomposite sorbent was $13.94 \mathrm{mg} \mathrm{g}^{-1}$. The presence of anions at various concentrations decreased the adsorption capacity by 0.86 to $5.74 \mathrm{mg} \mathrm{g}^{-1}$ (Table 6). The effect of anions on phosphate adsorption on the adsorbent was in the order of $\mathrm{SiO}_{3}{ }^{2-}>\mathrm{CO}_{3}{ }^{2-}>\mathrm{SO}_{4}{ }^{2-}>$ $\mathrm{NO}_{3}{ }^{-}$. This decreases readily adsorption capacity of phosphate ions. Generally, multivalent anions are absorbed more readily than monovalent anions. This phenomenon is closely correlated with charge-to-radius ratios of the anions which are in the order of $\mathrm{SiO}_{3}{ }^{2-}>\mathrm{CO}_{3}{ }^{2-}$ $(2 / 1.85),>\mathrm{SO}_{4}{ }^{2-}(2 / 2.3)>\mathrm{NO}_{3}{ }^{-}(1 / 1.89)$. As the ratio increases adsorption capacity and hence interference with phosphate ion increases.

Table 6. Effect of competing anions on the adsorption of phosphate on $\mathrm{Fe}-\mathrm{Al}-\mathrm{Mn}$ trimetal hyd(oxide) adsorbent at $25^{\circ} \mathrm{C}$. $\left(15 \mathrm{mg} \mathrm{P} \mathrm{L}^{-1}\right.$, adsorbent dose $=0.15 \mathrm{~g} \mathrm{~L}^{-1}, \mathrm{pH}=6.5$, ionic strength $=0.01 \mathrm{M}$, contact time $=24 \mathrm{~h})$.

\begin{tabular}{|l|c|c|c|c|c|c|c|c|c|}
\hline & & \multicolumn{6}{|c|}{ Competing anions and their concentrations (mg/L) } \\
\cline { 2 - 10 } & No anion & \multicolumn{2}{|c|}{$\mathrm{CO}_{3}{ }^{2-}$} & \multicolumn{2}{c|}{$\mathrm{SiO}_{3}{ }^{2-}$} & \multicolumn{2}{c|}{$\mathrm{SO}_{4}{ }^{2-}$} & \multicolumn{3}{c|}{$\mathrm{NO}_{3}{ }^{-}$} \\
\cline { 2 - 10 } & 0.0 & 10.0 & 20.0 & 10.0 & 20.0 & 10.0 & 20.0 & 10.0 & 20.0 \\
\hline $\mathrm{mg} \mathrm{P} \mathrm{L}^{-1}$ adsorbed & 13.94 & 10.89 & 9.32 & 11.68 & 8.20 & 12.94 & 11.88 & 13.86 & 13.48 \\
\hline$\% \mathrm{PO}_{4}{ }^{3-}$ adsorbed & 92.93 & 72.60 & 62.13 & 77.87 & 54.67 & 86.27 & 79.20 & 92.40 & 89.87 \\
\hline
\end{tabular}

\section{Phosphate sorption-desorption from soil solution}

The HFAMO extractable amounts of $\mathrm{P}$ over $42 \mathrm{~h}$ in the $\mathrm{P}$ treated soil are shown in Table 7 . The amount of $P$ extracted was significantly affected $(p<0.001)$ by the levels of $P$ applied. The highest cumulative $\mathrm{P}\left(38.78 \mathrm{mg} \mathrm{kg}^{-1}\right)$ was extracted from the sample treated with the highest $\mathrm{P}$ rate $\left(150 \mathrm{mg} \mathrm{P} \mathrm{kg}^{-1}\right)$ and this is $25.85 \%$ of the applied $\mathrm{P}$. This low desorbable amount of $\mathrm{P}$ is due to high contents of acidic cations in the soil that changed the applied $\mathrm{P}$ into insoluble forms. The cumulative desorbable amount of $\mathrm{P}$ was linearly proportional to the amount of $\mathrm{P}$ applied. This is because with increased applied $\mathrm{P}$, the active sorption sites of the soil colloids became saturated and the soil particle surface got largely negatively charged. This makes the negatively

Table 7. Cumulative HFAMO extractable phosphorus $\left(\mathrm{mg} \mathrm{kg}^{-1}\right)$ in soil (adsorbent dose $=0.15 \mathrm{~g} \mathrm{~L}^{-1}$; contact time $=42 \mathrm{~h})$.

\begin{tabular}{|c|c|c|c|c|c|c|c|}
\hline \multirow{2}{*}{ Treatments } & \multicolumn{7}{|c|}{ Sorption-desorption time (h) } \\
\cline { 2 - 8 } & 6 & 12 & 18 & 24 & 30 & 36 & 42 \\
\hline $\mathrm{P}_{0}$ & $0.036^{\mathrm{d}}$ & $0.352^{\mathrm{d}}$ & $0.873^{\mathrm{d}}$ & $1.504^{\mathrm{d}}$ & $2.647^{\mathrm{d}}$ & $2.29^{\mathrm{d}}$ & $2.017^{\mathrm{d}}$ \\
\hline $\mathrm{P}_{1}$ & $2.253^{\mathrm{c}}$ & $6.597^{\mathrm{c}}$ & $8.759^{\mathrm{c}}$ & $12.61^{\mathrm{c}}$ & $16.98^{\mathrm{c}}$ & $19.34^{\mathrm{c}}$ & $20.10^{\mathrm{c}}$ \\
\hline $\mathrm{P}_{2}$ & $4.661^{\mathrm{b}}$ & $8.638^{\mathrm{b}}$ & $14.99^{\mathrm{b}}$ & $19.547^{\mathrm{b}}$ & $22.62^{\mathrm{b}}$ & $24.97^{\mathrm{b}}$ & $24.93^{\mathrm{b}}$ \\
\hline $\mathrm{P}_{3}$ & $6.946^{\mathrm{a}}$ & $12.214^{\mathrm{a}}$ & $17.22^{\mathrm{a}}$ & $24.67^{\mathrm{a}}$ & $28.93^{\mathrm{a}}$ & $34.66^{\mathrm{a}}$ & $38.78^{\mathrm{a}}$ \\
\hline $\mathrm{CV}$ & 0.48 & 0.60 & 0.66 & 0.58 & 0.46 & 0.62 & 0.68 \\
\hline $\mathrm{F}-$ test & $* * *$ & $* * *$ & $* * *$ & $* * *$ & $* * *$ & $* * *$ & $* * *$ \\
\hline $\mathrm{R}^{2}$ & 0.942 & 0.982 & 0.999 & 0.982 & 0.842 & 0.822 & 0.899 \\
\hline LSD & 0.016 & 0.018 & 0.016 & 0.018 & 0.014 & 0.016 & 0.018 \\
\hline
\end{tabular}

$\mathrm{P}_{0} \mathrm{P}_{1}, \mathrm{P}_{2}$, and $\mathrm{P}_{3}$ are $\mathrm{P}$ rates $\left(\mathrm{mg} \mathrm{kg}^{-1}\right)$ at $0,50,100$ and $150 ; \mathrm{CV}=$ coefficient of variance; $\mathrm{LSD}=$ least significant difference; $\mathrm{R}^{2}=$ correlation coefficient; means down the column with the same superscript letters are not significantly different. The means separating superscript letters work only down the columns. 
charged phosphate $\left(\mathrm{PO}_{4}{ }^{3-}\right)$ loosely attracted and easily released. The desorbed amounts of $\mathrm{P}$ in the control sample were very small as the indigenous $\mathrm{P}$ of the soil was fixed by the acidic oxide through time.

As can be seen from Figure 9, desorption maximum were not reached for all of the treatments and release of $\mathrm{P}$ would continue for longer times than $42 \mathrm{~h}$. However, desorption rates were decreasing with time as $\mathrm{P}$ became fixed by the acidic cations like $\mathrm{Al}^{3+}, \mathrm{Fe}^{3+}$ etc trough time. This observation is consistent with the results of other studies [12, 22, 23]. Cumulative amount of adsorbed $\mathrm{P}$ increased rapidly with an increase of contact time, and equilibrium was achieved within about $30 \mathrm{~h}$. After equilibrium, there is only slow increment of phosphate adsorption and the amount of phosphate adsorbed remained almost steady until the end of the experiment $(42 \mathrm{~h})$.

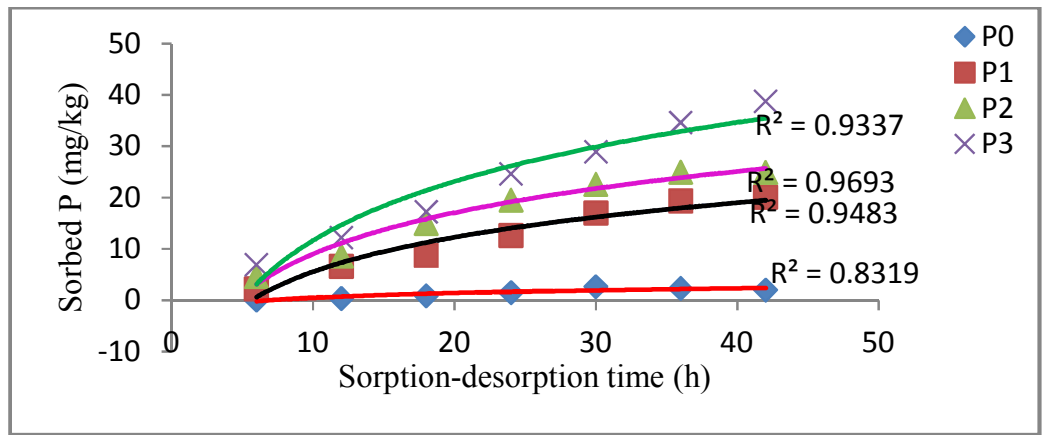

Figure 9. Kinetic curves of phosphate adsorption on nanocomposite adsorbent of Fe-Al-Mn trimetal hydr(oxide) (adsorbent dose $=0.15 \mathrm{~g} \mathrm{~L}^{-1}$; contact time $=42 \mathrm{~h}$ ).

The difference between $\mathrm{P}$ sorption on the nanocomposite sorbent from aqueous system (discussed on sections above) and soil solution is due to the fact that surface positive charges on the soil colloids compete with that on the sorbent surface. This makes the cumulative amount of sorbed P from soil solution relatively small. In addition, as contact time increased, the P fixing process traps larger amount of the soluble $\mathrm{P}$ and hence rate of $\mathrm{P}$ desorption became slower. Currently, we are devising a mechanism to avoid direct contact between the phosphate sink and the soil solution with the aim of developing a novel technique to evaluate the long-term $\mathrm{P}$ desorption kinetics from soil.

\section{CONCLUSION}

In this study, Fe-Al-Mn ternary oxide sorbent was developed by oxidation and coprecipitation methods from their precursor salts of ferrous sulfate heptahydrate $\left(\mathrm{FeSO}_{4} \cdot 7 \mathrm{H}_{2} \mathrm{O}\right)$, aluminum chloride $\left(\mathrm{AlCl}_{3}\right)$ and potassium permanganate $\left(\mathrm{KMnO}_{4}\right)$ in three different molar ratios: 3:3:1, $6: 3: 1$, and $2: 4: 1$. XRD results showed amorphous structures except the nanocomposite with 2:4:1 ratio where crystalline phase is identified. Among the three proportions, the 3:3:1 molar ratio of the $\mathrm{Fe}-\mathrm{Al}-\mathrm{Mn}$ mixed oxide system possessed the highest specific surface area $\left(243 \mathrm{~m}^{2} / \mathrm{g}\right)$ and was selected for phosphate sorption-desorption study. The phosphate was found to depend on $\mathrm{pH}$ showing a decreasing trend with the increasing of $\mathrm{pH}(4-10.5)$. The increase of ionic strength had no noticeable effect on phosphate adsorption. Based on this finding, it can be concluded that phosphate anions may be specifically adsorbed on the Fe-Al-Mn ternary oxide nanosorbent via forming inner-sphere surface complexes. The phosphate adsorption on the adsorbent was fitted to various isotherm models at $\mathrm{pH} 6.5$ with the ensuing order: Freundlich $>$ Temkin $>$ Dubinin-Radushkevich $>$ Langmuir. The maximum phosphate adsorption capacity 
of Fe-Al-Mn trimetal oxide was about $49.95 \mathrm{mg} \mathrm{g}^{-1}$ at $35{ }^{\circ} \mathrm{C}$. The kinetic data were described better by the pseudo-second-order adsorption kinetic rate model. The coexisting anions competed with phosphate to be adsorbed on the adsorbent in the order $\mathrm{SiO}_{3}{ }^{2-}>\mathrm{CO}_{3}{ }^{2-}>\mathrm{SO}_{4}{ }^{2-}>$ $\mathrm{NO}_{3}{ }^{-}$and this is closely correlated with charge-to-radius ratios of the anions. The Fe-Al-Mn trimetal hydr(oxide) nanocomposite sorbent with good specific affinity towards phosphate is a promising adsorbent for soil $\mathrm{P}$ desorption studies.

\section{ACKNOWLEDGEMENTS}

The authors would like to acknowledge the Research and Extension Office of Haramaya University (HURG-2014-03-03 and HURG-2016-03-02), Postgraduate Program Directorate office, Ministry of Education, Chemistry Department of $\mathrm{HU}$ and the School of Natural Resource Management and Environmental Sciences. The authors also kindly acknowledge the Spanish Research Council (CSIC) for characterizing the samples.

\section{REFERENCES}

1. Bhattacharya, S.; Das A.; Bhardwaj, S.; Sundara Rajan, S. Phosphate solubilizing potential of Aspergillus niger MPF-8 isolated from Muthupettai mangrove. J. Sci. Ind. Res. 2015, 74, 499-503.

2. Zach-Maor, A.; Semiat R.; Shemer H. Adsorption-desorption mechanism of phosphate by immobilized nano-sized magnetite layer: interface and bulk interactions. J. Colloids. Interf. Sci. 2011, 357, 440-446.

3. McDowell, R.; Sharpley, A. Phosphorus transport in overland flow in response to position of manure application. J. Environ. Qual. 2002, 31, 217-227.

4. Tofik, A.; Abi M. Taddesse; Tesfahun, K.; Girma, G. Fe-Al binary oxide nanosorbent: Synthesis, characterization and phosphate sorption property. J. Environ. Chem. Eng. 2016, 4, 2458-2468.

5. Buzuayehu, A.; Abi M. Taddesse; Tesfahun, K.; Endale, T.; Isabel D. Fe-Al-Mn ternary oxide nanosorbent: Synthesis, characterization and phosphate sorption property. J. Environ. Chem. Eng. 2017, 5, 1330-1340.

6. Li, F.B.; Li, X.Z.; Liu, C.S.; Liu, T.X. Effect of alumina on photocatalytic activity of iron oxides for bisphenol A degradation. J. Hazard. Mater. 2006, 149, 199-207.

7. Mohapatra, M.; Anand, S. Synthesis and applications of nano-structured iron oxides/hydroxides - a review. Int. J. Eng. Sci. Technol. 2010, 2, 127-146.

8. Zhang, G.S.; Liu, H.J.; Liu, R.P.; Qu, J.H. Removal of phosphate from water by a Fe-Mn binary oxide adsorbent. J. Colloids. Interf. Sci. 2009, 335, 168-174.

9. De Sousa, A.F.; Braga, T.P.; Chagas Gomes, E.C.; Valentini, A.; Longhinotti, E. Adsorption of phosphate using mesoporous spheres containing iron and aluminum oxide. Chem. Eng. J. 2012, 210, 143-149.

10. Lu, J.; Liu, H.; Zhao, X.; Jefferson, W.; Cheng, F.; Qu, J. Phosphate removal from water using freshly formed Fe-Mn binaryoxide: Adsorption behaviors and mechanisms. Colloids Surf. A: Physicochem. Eng. Asp. 2014, 455, 11-18.

11. Li, G.; Gao, S.; Zhang, G.; Zhang, X. Enhanced adsorption of phosphate from aqueous solution by nanostructured iron(III)-copper(II) binary oxides. Chem. Eng. J. 2014, 235, 124131.

12. Lu, J.; Liu, H.; , Liu, R.; , Zhao ,X.; Sun L.; Qu, J. Adsorptive removal of phosphate by a nanostructured Fe-Al-Mn trimetal oxide adsorbent. Powder Technol. 2013, 233, 146-154.

13. Sujana, M.G.; Anand, S. Fluoride removal studies from contaminated ground water by using bauxite. Desalination 2010, 267, 222-227. 
14. Lu, H.; Liu, R.; Liu, X.; Zhao, L.; Sun, J.Q. Adsorptive removal of phosphate by a nanostructured Fe-Al-Mn trimetal oxide adsorbent, Powder. Technol. 2013, 233, 146-154.

15. Laurent, S.; Forge, D.; Port, M.; Roch, A.; Robic, C.; Elst, L. V.; Muller, R.N.. Magnetic iron oxide nanoparticles: synthesis, stabilization, vectorization, physicochemical characterizations, and biological applications. Chem. Rev. 2008, 108, 2064-2110.

16. Murphy, J.; Riley, J.P. A modified single solution method for the determination of phosphate in natural waters. Anal. Chem. Acta 1962, 27, 31-36.

17. Chalachew, M.; Taddesse, Abi M.; Girma G.; , Teketel Y. Natural pigment sensitized solar cells based on $\mathrm{ZnO}-\mathrm{TiO}_{2}-\mathrm{Fe}_{2} \mathrm{O}_{3}$ nanocomposites in quasi-solid state electrolyte system. Bull. Chem. Soc. Ethiop. 2017, 31, 263-279.

18. Nejat, R.H.; Taddesse, Abi M.; Ayalew, T. Synthesis, Characterization and photocatalytic activity of $\mathrm{MnO}_{2} / \mathrm{Al}_{2} \mathrm{O}_{3} / \mathrm{Fe}_{2} \mathrm{O}_{3}$ nanocomposite for degradation of malachite green. Bull. Chem. Soc. Ethiop. 2018, 32, 101-109.

19. Naemi, Z.; Jafar-Tafreshi, M.; Fazli, M.; Studies on properties of $\mathrm{Ag} \backslash \mathrm{Al}_{2} \mathrm{O}_{3}$ nanocomposite synthesized by solution combustion technique under novel condition. J. Nanostruc. 2012, 2 , 183-189.

20. Lowell, S.; Shields, J.E.; Thomas, M.A.; Thommes, M. Characterization of Porous Materials and Powders: Surface Area, Pore Size and Density, Particle Technology Series: ISBN 1402023022; 2008.

21. Zhang, Y.; Wu, X.; Dou, X.; Yang, M. Fluoride removal performance of novel Fe-Al-Ce trimetal oxide adsorbents. Chemosphere 2007, 69, 1758-1764.

22. Luengo, C.; Brigante, M.; Avena, M. Adsorption kinetics of phosphate and arsenate on goethite: A comparative study. J. Colloids. Interf. Sci. 2007, 311, 354-360.

23. Shao, Z.H.; Stanforthm, R. Competitive adsorption of phosphate and arsenate on goethite. Environ. Sci. Technol. 2001, 35, 4753-4757.

24. Goldberg, S. Equations and Models Describing Adsorption Processes in Soils. Soil Chemical Processes in Soils, SSSA Book Series, Soil Science Society of America: USA; 2005, p $677 \mathrm{~S}$.

25. Liu, R.; Lina, C.; Xinze W.; Yanming S.; Yuan, W.; Hamidreza, A. Review of metal (hydr)oxide and other adsorptive materials for phosphate removal from water. J. Environ. Chem. Eng. 2018, 6, 5269-5286.

26. Harvey, O.R.; Rhue, R.D. Kinetics and energetics of phosphate sorption in a multicomponent $\mathrm{Al}(\mathrm{III})-\mathrm{Fe}(\mathrm{III})$ hydr(oxide) sorbent system, J. Colloids. Interf. Sci. 2008, 322, 384-393.

27. Huang, H.; Rong, H.; Li, X.; Tong, S,; Zhu, Z.; Niu, L.; Teng, M. Phosphate Removal from Wastewater Using Red Mud. J. Hazard. Mater. 2008, 158, 35-42.

28. Masue, Y.; Loeppert, R.H.; Kramer, T.A. Arsenate and arsenite adsorption and desorption behavior on coprecipitated aluminum: iron hydroxides, Environ. Sci. Technol. 2007, 41, 837-842.

29. Yang, X.F.; Wang, D.S.; Sun, Z.X.; Tang, H.X. Adsorption of phosphate at the aluminum (hydr)oxides-water interface: role of the surface acid-base properties. J. Colloid Surf. A: Physicochem. Eng. Asp. 2007, 297, 84-90.

30. Sposito, G. The Surface Chemistry of Soils, Oxford University Press: New York; 1984.

31. Chubar, N.I.; Kanibolotsky, V.A.; Strelko, V.V. Adsorption of phosphate ions on novel inorganic ion exchangers. J. Colloids Surf. A: Physicochem. Eng. Asp. 2005, 255, 55-63.

32. Chowdhury, S.R.; Yanful, E.K. Arsenic and chromium removal by mixed magnetitenanoparticles and the effect of phosphate on removal. J. Environ. Manage. 2010, 91, 22382247.

33. Stumm, W.; Morgan, J.J. Aquatic Chemistry: Chemical Equilibria and Rates in Natural Waters, 3rd ed., Wiley-Interscience: New York; 1996. 